\title{
One culture bridging two
}

\section{Samuel Ting, discoverer of the $\mathrm{J}$ particle, is a Chinese scientist living and working in the West. Here he talks to Christine King}

\begin{abstract}
SAMUEL Ting is an American citizen by "an accident of birth". His parents, both professors, were on a visit to Ann Arbor, Michigan, from China in 1936 when he was born. Ting says "my parents had hoped that I would be born in China, but I was born prematurely. Two months after my birth we returned to China."' During those early years, China was a country torn by war, so formal education was impossible until he was twelve. Ting remembers now that this lack of continuity in education was compensated by meeting the many scholars who frequently visited their home. Ting's present reputation for hard work and being a highly demanding task-master has its origins perhaps in these early years.
\end{abstract}

"Since both my parents were working, I was brought up by my maternal grandmother, who was a very courageous and determined person. My grandfather had lost his life in the first Chinese Revolution. After that my grandmother returned to school, became a teacher and brought up my mother alone. When I was very young, I of ten heard stories from them recalling the difficult lives they had, and the great efforts they made to provide my mother with a good education. Both of them left an indelible impression on me."

Ting attended schools in China and later Taiwan, and decided to return to the US to continue his education at the University of Michigan. "At the time, I knew very little English and had no idea of the cost of living in the US. In China, I had read that many American students go through college on their own resources. I informed my parents that I would do likewise. I arrived at Detroit Airport on 6 September 1956 with $\$ 100$, which at the time seemed more than adequate. I was somewhat frightened, did not know anyone and communication was difficult". These were hard years for Samuel Ting, competing constantly for scholarships.

In 1963, with a doctorate and as a Ford Fellow, he went to CERN (the European organisation for nuclear research in Geneva) and came under the guidance of Guiseppe Cocconi, working with the Proton Synchrotron.

After this initiation into European high energy physics, Ting returned to lecture at Columbia University. Here he worked with leading physicists including Steinberger, Schwartz, C.S. Wu, and T.D. Lee. It was during these years at Columbia that his then unfashionable - interest in electronpositron pair production began.

At the Cambridge Electron Accelerator an experiment on $\mathrm{e}^{+} \mathrm{e}^{-}$pair production in photon collisions with nuclear targets appeared to show a violation of quantum electrodynamics. (QED is the relativistic quantum theory of electromagnetism; it remains the most accurately tested of all physical theories.) Ting studied the apparent violation with increasing interest and eventually asked Willi Jentschke of the DESY (Deutches Electronen Synchrotron) laboratory in Hamburg about doing a pair production experiment at Hamburg. By this time Ting was fully committed to investigating the decay of photon-like particles, and searching for new particles which decayed to electron or muon pairs. In 1971 he returned with his group to the US and began experiments at the Brookhaven National Laboratory. It was here, in late 1974, that Ting and his group found evidence of a new, totally unpredicted and long-lived heavy particle, the J or psi-particle, which was subsequently shown to contain charmed quarks. For this work, Ting shared the Nobel Prize for physics in 1976 with Burton Richter.

With Ting's growing reputation as a leading physicist have come new problems. In the present political climate of growing intercourse between the US and China, Ting's participation is inevitable. His group at DESY was amongst the first to receive physicists from the Institute of High Energy Physics in Peking to work in the West. The Chinese Press consistently refer to visiting scientists like Ting, and fellow Nobelists Yang and Lee, as ChineseAmerican or just American. Ting however, is a totally apolitical figure. He categorically repeats "I am not interested in politics and never have been; I have never voted (in the US).

On his trip to China a few weeks ago, Ting was feted by the Chinese Academy of Sciences (CAS), and as on previous visits, talked privately with Chinese leaders Chairman Hua and Vice-premier Fang Yi, who is also president of the CAS. They talked of China's modernisation programme but, Ting says, they have never discussed political issues "probably because they already know my views".

Ting believes that since he goes to China to communicate with Chinese physicists, there is no time to sightsee. Each of his visits has been widely reported in the Chinese press, and every time his lectures have been attended by thousands. At first he had difficulty lecturing in Chinese (he has spent more of his life on the West than in China): "my audience of several thousand was hardly able to contain their mirth, and corrected me several times on scientific terminology. But 1 persisted and now it's no longer a problem."

To the outside world, China's decision to pursue high energy physics as part of its modernisation programme, is, to say the least, puzzling. "As I see it" said Ting, "although particle physics appears very complex, its fundamental principles are

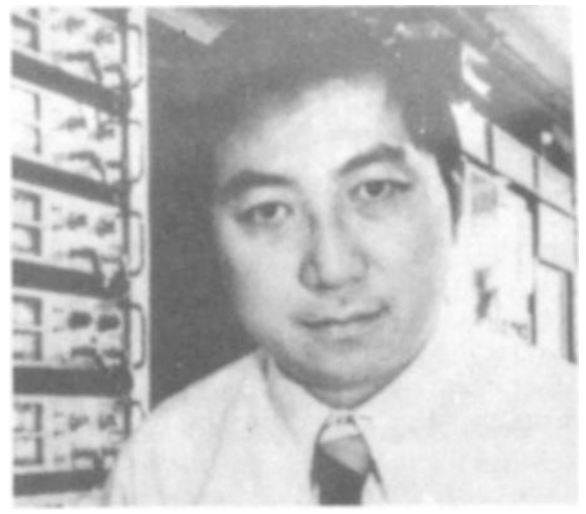

Samuel Ting: not interested in politics

nevertheless extremely simple . . Major discoveries are made by only a few individuals and China has plenty of these. It is an expensive pursuit, but it's also the most fundamental - and it's cheap by comparison to what's spent on defence, say." He believes that the Chinese will maintain their independence in high energy physics. But China's future scientific progress is not a subject which he, or anyone else outside China would feel qualified to predict.

Ting belongs to a new generation of jetsetting academics, spending much of his time at DESY, where he is pursuing the search for the intermediate vector boson at PETRA, currently the world's most sophisticated electron-positron colliding beam device. To keep abreast of his commitments at MIT where he is professor of physics, he flies between Boston and Hamburg on average once a fortnight.

Despite his reputation for working his team hard, no-one works harder than Ting himself. How does life in Hamburg differ from his life in the US? "My life in Hamburg is work, work and more work. As for my team, I try to choose only those who also like to work hard." Interviewing Ting can be a formidable experience if one expects any human foibles - in his own words, he does not smoke, drink or gamble, nor does he read fiction. His family now lives in the US, although the children spent many years in Germany. When he arrives home, do his children complain that they don't see enough of him? "Yes, all the time." Like many Chinese fathers, Ting is determined that his children should put their studies first. When I remarked that in talking of his children, he had repeatedly said only how he expected them to work hard and do well at school, Ting gave a rare laugh. "It's true - around the block where I live, I'm known as the 'bad guy', because I'm so strict with them."

When Ting is not pursing theoretical particle physics, his predilection is very much towards history. He regards Faraday as a notable historical figure, admiring not only his great breadth of vision but also the difficult and determined path by which he achieved his mastery of science. To be seen as another Faraday - no doubt that would be Samuel Ting's dream. 